\title{
Latent NORs in the species Pycnogaster cucullata (Orthoptera)
}

\author{
J. Santos,* \\ C. Sentís, \\ J. Garcia-Rodriguez $\dagger$ and \\ J. Fernández-Piqueras*
}

\author{
* Departamento de Biología, Unidad de Genética, \\ Mod. C-XV, Facultad de Ciencias, Universidad \\ Autónoma de Madrid, 28049-Madrid, Spain. \\ $\dagger$ Centro de Biología Molecular, Universidad \\ Autónoma de Madrid, 28049-Madrid, Spain.
}

The chromosomal location of the ribosomal cistrons $18+26 \mathrm{~S}$ and $5 \mathrm{~S}$ has been determined in spermatocytes of two cytological races of Pycnogaster cucullata by in situ hybridization using molecular probes from both types of rDNA. A comparative analysis with previous results suggested the existence of more $18+26 S$ rDNA sites than active NORs as shown by silver impregnation, but $5 S$ rDNA sites are outside the NORs. Thus, different categories of latent NORs have been shown in this specialised cell type which are discussed in relation to the evolutionary process of differentiation in this species.

\section{INTRODUCTION}

The species Pycnogaster cucullata has been studied in previous papers, and two cytological races were found differing by their sex chromosome system (XO and neo XY) (Fernández-Piqueras et al., 1982, 1983; Sentís et al., 1984). Silver impregnation in spermatocytes of this species has also served to demonstrate two different categories of Ag-NORs, named primary and secondary, which differ by the appearance and meiotic behaviour of their silver precipitates. Primary NORs are present in all primary spermatocytes from each individual whereas the other type (secondary NORs) seems to be dispensable and is only present in some individuals and even so, not in all primary spermatocytes of a given individual. In addition, other Ag-precipitates can be also observed at a very low frequency in the proximal region of the $\mathrm{X}$ chromosome (XO race), and five exceptional cells were found in a single male of the neo $X Y$ race which displayed a single active NOR at the distal secondary constriction of the $\mathrm{X}_{\mathrm{L}}$ arms of the neo $\mathrm{X}$ (Sentís et al., 1988).

We postulated that secondary NORs could be considered as a special category of latent NORs with variable transcriptional activity (Sentís et al., 1988). To check this hypothesis, in situ hybridization using molecular probes from both types of ribosomal cistrons $(18+26 \mathrm{~S}$ and $5 \mathrm{~S})$ have been accomplished in the two cytological races of the species $P$. cucullata.

\section{MATERIAL AND METHODS}

Ten males from each cytological race of the species Pycnogaster cucullata (Orthoptera) have been collected from natural Spanish populations at Sierra de Gredos (Puerto del pico, XO race) and Sierra de Guadarrama (Puerto de Morcuera, neo XY race). Individuals used in this study were injected with 0.03 per cent colchicine in insect saline solution $6 \mathrm{~h}$ prior to standard fixation of gonadal tissues in ethanol: acetic acid $(3: 1)$ for $2 \mathrm{~h}$. Meiotic chromosomes were obtained by the conventional squash method in a drop of 45 per cent acetic acid, and the coverslips were removed after immersing the slides in liquid nitrogen. The samples were then air dried for $15 \mathrm{~min}$. One hundred meiotic cells were studied for each probe and individual.

The molecular probes used in this study have been obtained from Artemia salina. The $16.5 \mathrm{~kb}$ insert of clone pArtI contains the full $18+26 \mathrm{~S}$ rRNA coding region and a considerable part of the non-transcribed spacer (NTS). The $700 \mathrm{bp}$ insert of clone pVC9 contains the entire 5S rRNA coding region and a small part of adjacent regions. Clones were labelled by nick translation with $\left({ }^{3} \mathrm{H}\right)$ dTTP according to the method described by Rigby 
et al. (1977). In situ hybridization of rDNA probes was carried out following the procedure described by Pardue (1986). Slides were immersed in Kodak NTB2 emulsion and stored 4-7 days at $4^{\circ} \mathrm{C}$. Autoradiographs were developed with D-19 and stained with 2 per cent Giemsa.

\section{RESULTS}

The chromosomal sties for ribosomal DNA were observed in meiotic chromosomes (fig. 1). Those sites where labelling was found to occur symmetrically in both homologues and in more than 50 per cent of the examined cells (up to a maximum of 80 per cent) were considered as major sites. In addition, some minor sites were also observed in less than 50 per cent (from 10 to 50 per cent) of the examined cells; these did not occur symmetrically in both homologues. Interspersed silver grains have also been observed in other chromosomal sites in less than 10 per cent of the cells. They could be considered as non-specific labelling, in spite of the relative absence of background. The observed differences in the frequency of labelling at specific sites could be explained if we accept some variations in the amount of rDNA and/or a
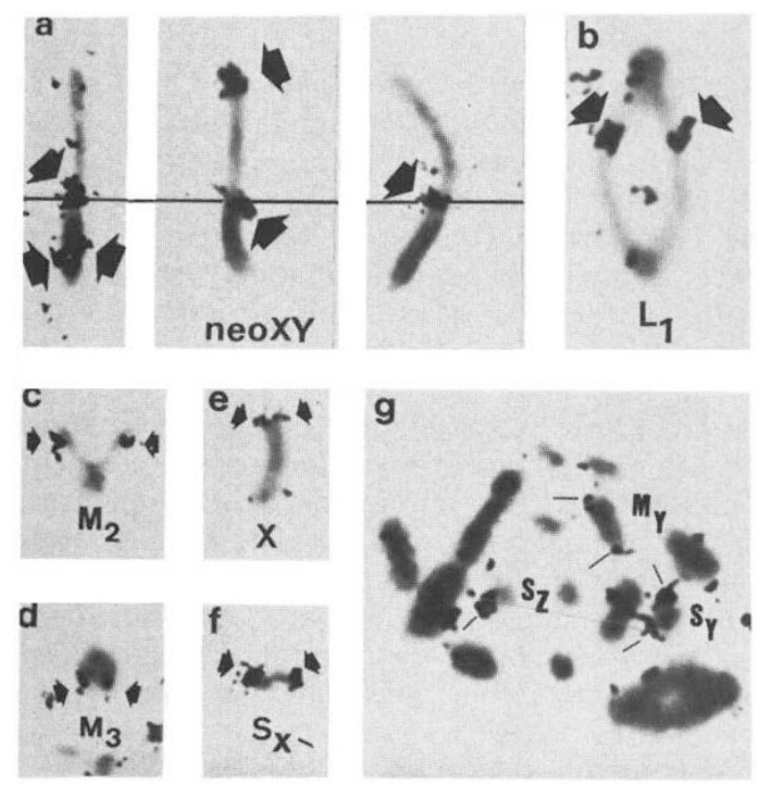

Figure 1 Labelling of meiotic chromosomes. (a-f) Chromosomal location of $18+26 \mathrm{~S}$ rDNA (dark arrows). (g) Metaphase I cell showing 5S rDNA sites located at the $M_{Y}$ bivalent and at the two short chromosome pairs $\left(S_{Y}\right.$ and $\mathrm{S}_{\mathrm{Z}}$ ) (lines).

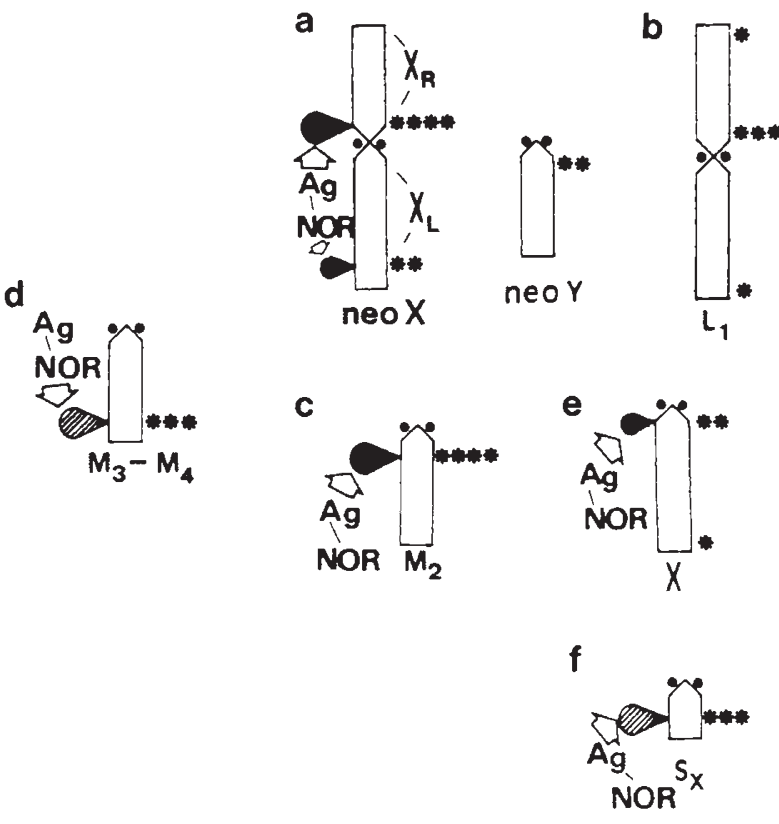

Figure 2 Interpretative diagrams showing the comparison of Ag-staining (Sentís et al., 1988) and "in situ" hybridization of $18+26 \mathrm{~S}$ results. Dark areas indicate active primary NORs, and striped areas denote active secondary NORs (Ag-NORs). Asterisks represent the chromosomal location and the cell frequency of labelling $\left({ }^{*}\right.$, less than 50 per cent of the analyzed cells. ${ }^{* *}$, from $50-60$ per cent. ${ }^{* *}$, from $60-70$ per cent. $* * * *$, from 70 per cent to a maximum of 80 per cent).

differential accessibility to molecular probes due to the chromatin conformation at these regions (fig. 2).

\section{Chromosomal location of $18+26 S$ rDNA}

\section{$X O$ race}

Up to six major sites have been shown which are located at the proximal regions of chromosomes $\mathrm{L}_{1}, \mathrm{M}_{2}$ and $\mathrm{X}$, at the distal region of two medium sized chromosomes $\left(\mathrm{M}_{3}\right.$ and $\left.\mathrm{M}_{4}\right)$, and at an unidentified short chromosome $\left(\mathrm{S}_{\mathrm{x}}\right)$ (figs. 1(b, c, $\mathrm{d}$, e and f) and 2).

\section{XY race}

This race differs from the $\mathrm{XO}$ race because two major sites can be shown on chromosome neoX, one is close to the centromere and the other is at a distal position in the $\mathrm{XL}$ arm (which derives from a primitive $\mathrm{X}$ at $\mathrm{XO}$ state). Another proximal major site can be observed on the chromosome neo $\mathrm{Y}$ (fig. 1a and 2). 
Minor sites for $18+26 \mathrm{~S}$ rDNA have been located at the telomeric regions of $\mathrm{L} 1$ ( $\mathrm{XO}$ and neo $X Y$ races) and $X$ ( $X O$ race) chromosomes (fig. 1 (b and e) and 2).

\section{Chromosomal location of $5 S$ rDNA}

The chromosomal sites for these cistrons are not coincident with those of $18+26 \mathrm{~S}$ rDNA, and have been located for both races at the paracentromeric regions of a medium sized bivalent $\mathbf{M}_{Y}\left(\mathbf{M}_{5}\right.$ or $M_{6}$ ), and on two short bivalents apparently shorter than those carrying $18+26 \mathrm{~S}$ sites $\left(\mathrm{S}_{\mathrm{Y}}\right.$ and $\left.\mathrm{S}_{\mathrm{Z}}\right)$. Nevertheless, the precise location of silver grains is difficult to ascertain in the short bivalents due to their extremely small size (fig. $1(\mathrm{~g})$ ). Chromosomes hybridized with the $5 \mathrm{~S}$ probe usually show less labelling than that displayed with the $18+26 \mathrm{~S}$ probe and silver grains are only observed in 40-60 per cent of the analysed cells.

\section{DISCUSSION}

Nucleolar organizer regions (NORs) have been described as those chromosomal sites which consist of the $18+26 \mathrm{~S}$ rDNA sequences whereas $5 \mathrm{~S}$ rDNA is usually outside the NORs in higher eukaryotes (Steffensen and Duffey, 1974; Vitelli et al., 1982). Silver impregnation has been widely used as a fast and reliable method to identify active NORs during both mitotic and meiotic divisions (Goodpasture and Bloom, 1975; Hofgartner et al., 1979), but the correspondence between Ag-NORs and the chromosomal location of the two ribosomal cistrons as shown by in situ hybridization is still controversial. Thus, Ag-NORs and $18+26 \mathrm{~S}$ rDNA sites show an exact correlation in mammals (Tantravahi et al., 1976), but in the parthenogenetic species Warramaba virgo only the chromosomal location of the $5 \mathrm{~S}$ ribosomal cistrons can be seen on the mitotic metaphases by silver staining (White et al., 1982). Furthermore, Schmid (1978) has described in Rana catesbeiana two different categories of NORs with Ag-staining named standard NOR and small NOR respectively. In situ hybridization of rDNA showed that standard NORs always hybridized with ribosomal $18+28 \mathrm{~S}$ cistrons while at least one small NOR corresponded with the location of 5S rDNA sites (Vitelli et al., 1982). All these data seem to indicate that silver impregnation is able to demonstrate either both types of active ribosomal cistrons or only one, depending on the analyzed species.
The chromosomal location of the $18+26 \mathrm{~S}$ rDNA sites in the species $P$. cucullata reveals that all the previously described Ag-NORs (Sentís et al., 1988), including primary and secondary AgNORs as well as those rarely observed in chromosomes X (proximal) and neoX (distal), consistent of $18+26 \mathrm{~S}$ rDNA, whereas $5 \mathrm{~S}$ ribosomal cistrons are located outside Ag-NORs (fig. 2).

These results confirm that secondary Ag-NORs in this species could be a special category of latent NORs (facultative latent NORs), which should be in turn under cellular controls related to the cellular requirements of ribosomal RNA synthesis in spermatocytes.

Nevertheless, there are two major chromosomal sites at the centromeric regions of $L_{1}$ and $Y$ chromosomes which hybridize with the $18+26 \mathrm{~S}$ probes but are not revealed by silver impregnation. In relation to the inactive ribosomal cistrons located on the $\mathrm{L}_{1}$ chromosomes of $P$. cucullata it is worth noting that an active Ag-NOR had been located at the same position in the $L_{1}$ of the related species P. finotii (Sentís et al., 1988). Thus, this NOR could be considered as a strictly latent NOR in P. cucullata similar to those described by King (1980) in the genus Litoria. It is conceivable that the inactivity or activity of this NOR is species specific. The existence of such latent NORs could be explained by the alteration of some factors which regulate the expression of these ribosomal cistrons, or by structural modifications of the rDNA itself during the evolutionary differentiation of the genus Pycnogaster. This may be reinforced by data reported in mammals, where speciesspecific transcription factors for rRNA genes have been described, and also by evidence for enhancer elements in rDNA of Xenopus species that occur in variable numbers in different ribosomal genes (see Reeder, 1985 for review).

With regard to minor labelled sites for $18+26 \mathrm{~S}$ rDNA, they could also be considered as latent NORs. However, these sites coincide with some telomeric regions and it may be argued that the rDNA probe cross-hybridize with $(\mathrm{G}+\mathrm{C})$ sequences as those demonstrated in the telomeres of many species of eukaryotes (Allshire et al., 1989).

In conclusion, we can distinguish two categories of latent NORs in $P$, cucullata. The strictly latent NORs consist of ribosomal cistrons $(18+26 \mathrm{~S}$ rDNA) which do not show nucleolar activity, at least in one very specialised cell type (spermatocytes). This could be the case of the ribosomal cistrons located at the $\mathrm{L}_{1}$ chromosomes (fig. 1(b)). The second type, so called facultative latent NORs, include those $18+26 \mathrm{~S}$ rDNA sites 
which show a variable transcriptional activity within a single individual, thus suggesting the existence of a cellular control for the rRNA synthesis.

Further experiments should be performed on other cell types, in order to obtain a more general view of the types and behaviour of latent NORs in the species Pycnogaster cucullata.

Acknowledgements We wish to thank Dr Jaime Renar who kindly provided us rDNA clones that have been used in the present study. This work was supported by a grant from the Spanish CICYT PB 87/114.

\section{REFERENCES}

Allshire, R. C., Dempster, M. AND hastie, N. D. 1989. Human telomeres contain at least three types of G-rich repeat distributed non-randomly. Nucleic Acid. Res., 17, 4611-4627.

FERNANDEZ-PIQUERAS, J., RODRIGUEZ-CAMPOS, A., SENTISCASTAÑo, C. AND WANDOSELl JURADO, F. 1982. Pycnogaster cucullata (Charp.): A polytypic species of tettigonioidea with $\mathrm{XO}$ and neoXY sex determination. Heredity, 48, 147-150.

FERNANDEZ-PIQUERAS, J., RODRIGUEZ-CAMPOS, A., SENTISCASTAÑo, C. AND RoJo-garCiA, E. 1983. Sex chromosome evolution in the polytypic species Pycnogaster cucullata. Heredity, 50, 217-223.

GOODPASTURE, C. AND BLOOM, S. E. 1975. Visualization of nucleolar organizer regions in mammalian chromosomes using silver staining. Chromosoma, 53, 37-50.

HOFGARTNER, F. J., SCHMID, M., KRONE, W., ZENZES, M. T. AND ENGEL, W. 1979. Pattern of activity of nucleolus organizer during spermatogenesis in mammals as analyzed by silver staining. Chromosoma, 71, 197-216.
KING, M. 1980. C-banding studies on Australian hylid frogs: secondary constriction structure and the concept of euchromatin transformation. Chromosoma, 80, 191-217.

PARDUE, M. L. 1986. In situ hybridization to DNA of chromosomes and nuclei. In Drosophila a Practical Approach. IRL Press, Washington, pp. 111-137.

REEDER, R. H. 1985. Mechanisms of nucleolar dominance in animals and plants. J. Cell Biol., 101, 2013-2016.

RIGBY, P. W. J., DIECKMANN, M., RHODES, C. AND BERG, P. 1977. Labeling deoxyribonucleic acid to high specific activity in vitro by nick translation with DNA polymerase I. J. Mol. Biol., 113, 237-251.

SCHMID, M. 1978. Chromosome banding in Amphibia. I. Constitutive heterochromatin and nucleolus organizer regions in Bufo and Hyla. Chromosoma, 66, 361-388.

SENTIS, C., RODRIGUEZ-CAMPOS, A., STOCKERT, J. C. AND FERNANDEZ-PIQUERAS, J. 1984. Morphology of the axial structures in the neo XY sex bivalent of Pycnogaster cucullata (Orthoptera) by silver impregnation. Chromosoma, 90 , 317-321.

SENTIS, C., SANTOS, J. AND FERNANDEZ-PIQUERAS, J. 1988. Primary and secondary nucleolar organizer regions during spermatogenesis in the genus Pycnogaster. Heredity, 60 , 197-204.

STEFFENSEN, D. M. AND DUFFEY, P. 1974. Localization of 5S ribosomal DNA genes on human chromosome 1. Nature, $252,741-743$.

TANTRAVAHI, R., MILLER, D. A., DEV, V. G. AND MILLER, O. J. 1976. Detection of nucleolus organizer regions in chromosomes of human, chimpanzee, gorilla, orangutan and gibbon. Chromosoma, 56, 15-27.

VITELLI, L., BATISTONI, R., ANDRONICO, F., NARDI, I. AND BARSACCHI-PILONE, G. 1982. Chromosomal localization of $18+28 \mathrm{~S}$ and $5 \mathrm{~S}$ ribosomal RNA genes in evolutionary diverse anuran amphibians. Chromosoma, 84, 475-491.

WHITE, M. J. D., DENNIS, E. S., HONEYCUTT, R. L., CONTRERAS, N. AND PEACOCK, W. J. 1982. Cytogenetics of the parthenogenetic grasshopper Warramaba virgo and its bisexual relatives. IX. The ribosomal cistrons. Chromosoma, 85, 181-199. 